\title{
Effectiveness of the influence of rehabilitation physical education on the psychological and physical status of people
}

\author{
Danil Dychko ${ }^{1 *}$, Vladyslav Dychko ${ }^{1}$,Elena Dychko ${ }^{1}$, Grigory Grigorenko ${ }^{1}$, and Sergey \\ Kokhan $^{2}$ \\ ${ }^{1}$ Donbas state pedagogical university, Vchytelska street 48a, Slavyansk, Ukraine \\ ${ }^{2}$ Transbaikal State University, Chita, Russia
}

\begin{abstract}
The research work deals with the actual problem of visual impairment in children at an early age, which creates difficulties in the accumulation of sensory experience, which delays the formation of mental processes. Children with visual impairments have specific peculiarities of activity, communication and psychophysical development, which are manifested in lagging, impairment and originality of the development of motor activity, spatial orientation, the formation of ideas and concepts, in the methods of object and practical activity, in the peculiarities of the emotional and volitional sphere, social communication, integration into society, adaptation to work. The authors developed a rehabilitation complex of physical exercises and studied the effectiveness of its influence on the psychophysical status of children and adolescents at the age of 10-16 years with visual impairments. In the course of the study (groups of children with visual impairment at the age of 10-14 and 15-16 years), it was found that the author's rehabilitation complex of physical exercises has a positive effect on the performance of tests characterizing the psychomotor reaction to a simple auditory and motor reaction, the sound version of the corrective test, contact coordination, hand strength and endurance, tapping test (strength of the nervous system) in children with visual impairment, and it can be recommended for widespread use by specialists to work with children at the age of 10-16 years with visual impairments to improve the psychophysiological state and improving the quality of life.
\end{abstract}

\section{Introduction}

Psychophysical status includes many concepts based on the motor abilities of the individual, which provide the level of his adaptation to different types of physiological activity.

Psychophysical status is a combination of innate anthropometric, morphological, psychological, physiological and biochemical characteristics of a man and it is directed at the success of physical or mental activity [1-5]. Psychophysical development is characterized by motor ability, mobility in the joints, coordination abilities of movements, the formation of

\footnotetext{
* Corresponding author: art-profi-1@yandex.ru
} 
children's coordination abilities in the process of development, the ability to control movements [6-9].

The gradual development of morphological and functional systems of the body with some advantage of the growth rate of the body relative to its weight is characterized for children at the age of 10-16 years. At this age, the ossification of the skeleton continues, although it still contains a significant amount of cartilage, formed cervical and thoracic curves. The ligament apparatus has a high elasticity, the flexor muscles are superior to the extensors, the muscles of the torso predominate over the muscles of the limbs, the relative strength of the limbs is close to that of adults. At this age there is a restructuring of the cardiovascular, respiratory, hematopoietic, immune, endocrine, nervous and other systems of the body of children $[10$, 11].

The need to ensure the process of restoration of impaired mental functions, among which motor functions stand out and creates a special importance in solving the problem of psychomotor development. Within our study we turn to the state of vision of the child, which largely determines the formation of the image of the outside world, according to which the psychological system of a child with visual impairment, its features, ability to reflect the perceived world in all its complex relationships and social life [12-14].

The scientific researches in this field allow us to conclude that a significant reduction or complete absence of visual sensations, perceptions, representations in sensory cognition limits the ability to form images of imagination, memory, and psychological systems, their structures, connections, functions and relationships within these systems. There are qualitative changes in the system of relations of analyzers; there are specific features in the formation of images, concepts, speech, in the ratio of figurative and conceptual in mental activity, in orientation and mobility in space, etc. The significant changes occur in physical development - the accuracy of movements, their intensity is disturbed, gait and other motor acts become specific [15].

Therefore, his own very peculiar psychological system is formed in children, which is both qualitatively and structurally different from the system of a normally developing child, as it includes processes at different levels of development due to the influence of the primary defect, as well as its correction on the basis of creation of new compensatory ways of development. This shows that interfunctional connections in children with visual impairment are also carried out differently, in a peculiar way $[16,17]$.

The conclusions from the study of A.G. Litvak, L.I. Plaksinoi indicates that visual impairment in a child from an early age creates difficulties in the spontaneous accumulation of sensory experience, which delays the formation of mental processes. Persons with visual impairments have specific features of activity, communication and psychophysical development. They are manifested in the lag, violation and originality of motor activity, spatial orientation, formation of ideas and concepts, in the methods of subject-practical activity, in the features of the emotional-volitional sphere, social communication, integration into society, adaptation to work $[18,19]$.

In contrast to children with normal development, scientists have identified the following features of the formation of psychomotor skills: slow movements in the formation of posture or excessive fussiness; difficulty maintaining posture, impaired static coordination; disorders of dynamic coordination and switchability; difficulties in the spatial organization of movement; difficulties in following verbal instructions; tension, stiffness of finger movements; violations of the pace of movement [20, 21].

Motor activity has a decisive influence on the formation of the brain, psychophysical, sensory, intellectual and mental abilities of the child. The development of fine motor skills of the hand plays a particularly important role as the hand has the largest representation in the cerebral cortex and is adjacent to such important centers as speech, visual, coordination, etc., being in close contact and functional unity with these centers. 
In order to prevent the formation and development of the psychological system of children with visual impairments, is directly related to the correctional work which is being carried out by us, and the formation of their compensatory processes, we used in our work a set of rehabilitation physical education that promotes motor activity.

The effectiveness of the impact of rehabilitation physical education on the psychological and physical status of children with visual impairment is determined by a number of indicators: the level of functionality, the average value of reaction time, reaction stability, number of premature reactions, mental performance. Nowadays, in our conditions, a system of rehabilitation physical education for the psychophysical status of children with visual impairment is being formed. The analysis of the literature has shown that this aspect has not been studied enough.

The study of the peculiarities of rehabilitation physical education on the psychological and physical status of children with visual impairment allowed us to form and test a number of methods, which in turn made it possible to draw evidence-based conclusions.

The purpose of the research. The study of the effectiveness of the influence of the developed complex of rehabilitation physical education on the psychological and physical status of children and adolescents at the age of 10-16 years with visual impairments.

\section{Materials and methods}

The bases for the study were: a specialized boarding school for blind and partially sighted children of I - III degrees № 23 in Sloviansk, Donetsk region (Ukraine).

The developed phased technology of rehabilitation and limitation of retardation of children and adolescents at the age of 10-16 years with visual impairment was developed by us and it was applied among 40 children with visual impairment (18 boys and 22 girls) at the age of 10-14 years and 30 children ( 12 boys and 18 girls) at the age of 15-16 years with visual impairment.

All psychophysiological functions in the body, psychomotor organization and motor abilities of children in the control group and children with visual pathology were considered from the standpoint of functional-genetic approach, which is the fundamental theoretical basis of modern differential psychophysiology.

To solve the tasks, the registration of the particular time of the reaction of the parameters was performed using the hardware and software complex "NS-PsychoTest-NO" NSFT010999.001PS - Neurosoft, under the guidance of the operating system Windows XP Professional. The experimental implementation of rehabilitation technology for children and its effectiveness in assessing the indicators of physical development: psychomotor qualities in the children under research, properties of nervous processes and functional states were evaluated on the basis of the parameters of the reaction by the following classical psychodiagnostic techniques: "Simple auditory-motor response", "Corrective test (sound) ". The analysis of motor features - psychological and physiological diagnosis of properties of nervous processes and functional states on the basis of indicators of motor features: "Assessment of muscular endurance", "Tapping test", "Coordinationometry".

The effective development of physical qualities in children with visual impairments is due primarily to the selection and implementation of rehabilitation measures to increase the level of general physical fitness, taking into account the individual age development of the child.

We used the method of physical exercises for the rehabilitation of children with visual impairments. An exercise plan has been developed taking into account age, sex and depth of the degree of violation of indicators.

Each complex of rehabilitation physical education, which was used for children with pathology at the age of 10 - 16 years, consisted of 13-15 special exercises, each of which was 
performed 6-10 times in one approach, taking into account the individual abilities of each person: gender, age, diagnosis. At the same time, each complex of rehabilitation physical education was characterized by duration, intensity of exercises, nature of rest and its duration. Rest intervals were determined by the well-being and assessment of the rehabilitation specialist, that is they were conditional.

The research was conducted in accordance with the provisions of the Council of Europe Convention on the Protection of Human Rights and Dignity in Biomedicine (1997), "Ethical Principles for Medical Research with Human Subjects" adopted by the 52nd Assembly of the World Medical Association (2000), on Bioethics and Human Rights ", adopted by the resolution of the General Conference of UNESCO (2005), the principles of the Declaration of Helsinki (1964) and compliance with current regulations of Ukraine.

Parents of all children gave informed written consent for the examination of their children and the use of the obtained data in scientific work. Statistical processing of the obtained results was performed according to the well-known methods of variable statistics with determination of mean values $(\mathrm{M})$ and standard error $( \pm \mathrm{m})$. The reliability of these independent samples was calculated by the Student's t-test. The difference was considered significant at $\mathrm{P}>0.05$.

\section{Results}

The results of the study of the effectiveness of the implementation of the developed comprehensive phased method of rehabilitation in children at the age of 10-14 years with visual pathology on the indicators of a simple auditory-motor response 1 .

Table 1. The indicators of PSMR in children at the age of 10-14 years with visual impairments after rehabilitation physical education.

\begin{tabular}{|c|c|c|c|}
\hline \multirow[t]{2}{*}{ Indicators } & \multirow{2}{*}{$\begin{array}{c}\text { Unites of } \\
\text { measurement }\end{array}$} & \multicolumn{2}{|c|}{ Boys } \\
\hline & & $\begin{array}{c}\text { Before rehabilitation } \\
n-18 \\
\end{array}$ & $\begin{array}{c}\text { After rehabilitation } \\
\text { n-18 } \\
\end{array}$ \\
\hline Total number of errors & un. & $5.72 \pm 0.26$ & $4.01 \pm 0.18$ \\
\hline Level of functional opportunities & $1 / \mathrm{s}^{2}$ & $3.30 \pm 0.11$ & $4.22 \pm 0.14$ \\
\hline The average value of reaction time & $\mathrm{ms}$ & $234.52 \pm 13.14$ & $166.51 \pm 9.33$ \\
\hline Stability of reaction & $\mathrm{ms}$ & $1.50 \pm 0.04$ & $1.05 \pm 0.03$ \\
\hline Functional level of the system & un & $3.90 \pm 0.13$ & $5.03 \pm 0.16$ \\
\hline Number of premature reactions & un & $1.00 \pm 0.19$ & $0.72 \pm 0.14$ \\
\hline \multirow[b]{2}{*}{ Indicators } & \multirow{2}{*}{$\begin{array}{c}\text { Unites of } \\
\text { measurement }\end{array}$} & \multicolumn{2}{|c|}{$\begin{array}{l}\text { Girls } \\
\end{array}$} \\
\hline & & $\begin{array}{c}\text { Before rehabilitation } \\
n-22\end{array}$ & $\begin{array}{l}\text { After rehabilitation n- } \\
\qquad 22\end{array}$ \\
\hline Total number of errors & un & $3.59 \pm 0.11$ & $2.80 \pm 0.09$ \\
\hline Level of functional opportunities & $1 / \mathrm{s}^{2}$ & $3.00 \pm 0.10$ & $3.66 \pm 0.12$ \\
\hline The average value of reaction time & $\mathrm{ms}$ & $254.90 \pm 13.14$ & $201.37 \pm 10.38$ \\
\hline Stability of reaction & $\mathrm{ms}$ & $1.40 \pm 0.06$ & $1.12 \pm 0.05$ \\
\hline Functional level of the system & un & $3.90 \pm 0.10$ & $4.75 \pm 0.12$ \\
\hline Number of premature reactions & un & $0.68 \pm 0.11$ & $0.53 \pm 0.09$ \\
\hline
\end{tabular}

After the physical exercises included in the rehabilitation complex on the indicators characterizing PSMR of an organism of children of 10-14 years with pathology of sight, the positive tendency on their improvement is revealed. In boys, the total number of errors decreases by $42.64 \%$, in girls - by $28.21 \%$; the level of functionality in boys increases by $27.88 \%$, in girls - by $22.0 \%$; the average value of the reaction time in boys by $40.84 \%$, in girls by $26.58 \%$; the level of stability of the reaction in girls increases by $25.0 \%$, in boys - by $42.86 \%$, the functional level of the system increases in girls by $21.79 \%$, and in boys - by $28.97 \%$ and the number of premature reactions in boys decreases by $38.81 \%$, for girls - by $28.30 \%$. According to table. 1 . it is seen that the complex phased technology of rehabilitation 
leads at the age of 10-14 years with pathology of sight to improvement of all indicators of simple auditory-motor reaction. The level of improvement depends on the sex of the children. The developed technology is more effective for boys than for girls.

The results of the study of the impact of a comprehensive sound methodology of rehabilitation measures in children at the age of 15-16 years with visual impairment on the indicators of PSMR are shown in table 2.

Table 2. The indicators of PSMR in children at the age of 15-16 years with visual impairments after rehabilitation physical education.

\begin{tabular}{|c|c|c|c|}
\hline \multirow[t]{2}{*}{ Indicators } & \multirow{2}{*}{\begin{tabular}{|c|} 
Unites of \\
measurement
\end{tabular}} & \multicolumn{2}{|c|}{ Boys } \\
\hline & & $\begin{array}{c}\text { Before } \\
\text { rehabilitation } \\
\text { n-12 }\end{array}$ & $\begin{array}{c}\text { After rehabilitation } \\
n-12\end{array}$ \\
\hline Total number of errors & un & $4.33 \pm 0.44$ & $3.12 \pm 0.32$ \\
\hline Level of functional opportunities & $1 / s^{2}$ & $3.20 \pm 0.20$ & $4.10 \pm 0.25$ \\
\hline The average value of reaction time & $\mathrm{ms}$ & $251.19 \pm 23.47$ & $183.37 \pm 17.14$ \\
\hline Stability of reaction & $\mathrm{ms}$ & $1.40 \pm 0.10$ & $1.01 \pm 0.07$ \\
\hline Functional level of the system & un & $4.00 \pm 0.27$ & $5.04 \pm 0.33$ \\
\hline Number of premature reactions & un. & $0.67 \pm 0.18$ & $0.49 \pm 0.13$ \\
\hline \multirow[b]{2}{*}{ Indicators } & \multirow{2}{*}{$\begin{array}{c}\text { Unites of } \\
\text { measurement }\end{array}$} & \multicolumn{2}{|c|}{ Girls } \\
\hline & & $\begin{array}{c}\text { Before } \\
\text { rehabilitation } \\
\text { n-18 }\end{array}$ & $\begin{array}{c}\text { After rehabilitation } \\
n-18\end{array}$ \\
\hline Total number of errors & un & $3.61 \pm 0.19$ & $2.53 \pm 0.14$ \\
\hline Level of functional opportunities & $1 / \mathrm{s}^{2}$ & $3.50 \pm 0.18$ & $4.55 \pm 0.24$ \\
\hline The average value of reaction time & $\mathrm{ms}$ & $213.52 \pm 8.94$ & $153.74 \pm 6.44$ \\
\hline Stability of reaction & $\mathrm{ms}$ & $1.80 \pm 0.13$ & $1.28 \pm 0.09$ \\
\hline Functional level of the system & un & $4.10 \pm 0.12$ & $5.33 \pm 0.15$ \\
\hline Number of premature reactions & un & $0.39 \pm 0.13$ & $0.28 \pm 0.09$ \\
\hline
\end{tabular}

The conducted physical exercises, which are provided by the technology of rehabilitation measures developed by us, revealed a positive effect on the improvement of the value of PSMR indicators at the children of the age of 15-16 years with visual impairments. After exercise, the total number of errors in boys decreased by $38.7 \%$, and in girls - by $42.69 \%$; the level of functional capabilities in boys at the age of $15-16$ years with visual pathology increased by $28.13 \%$, in girls - by $30.0 \%$; the average value of reaction time decreased in boys by $36.99 \%$, in girls - by $38.88 \%$; indicators of stability of reaction in boys by $38,61 \%$, in girls - by $40,63 \%$; the level of functional activity of the system increased in boys by $26.0 \%$, in girls - by $30.0 \%$ and decreased the number of premature reactions in boys by $36.73 \%$, in girls - by $39.29 \%$.

The results of the study of the influence of the developed comprehensive rehabilitation program of physical exercises on the indicators characterizing the sound version of the correction test in children 10-14 years old with visual impairments are given in table 3 .

The conducted complex phased technology of rehabilitation physical measures at the age of 10-14 years with pathology of sight promotes improvement of performance of indicators of a sound variant of the proofreading test. In boys aged 10-14 years with visual pathology, the number of errors decreased by $38.96 \%$, in girls - by $33.12 \%$; increased mental performance by $27.02 \%$ in boys and $23.88 \%$ in girls; the average reaction time decreases in boys - by $35.13 \%$ in girls - by $31.58 \%$; increases the stability of attention and working memory (intellectual attention) by $28.18 \%$ in boys and $24.82 \%$ in girls; the number of false reactions in boys decreased by $36.92 \%$, in girls - by $29.91 \%$ and the number of passes decreased by $36.44 \%$ in boys and by $33.33 \%$ in girls. 
Table 3. The influence of rehabilitation physical exercises on the indicators of the sound version of the correction test in children with visual impairments at the age of 10-14.

\begin{tabular}{|c|c|c|c|}
\hline \multirow[t]{2}{*}{ Indicators } & \multirow{2}{*}{$\begin{array}{c}\text { Unites of } \\
\text { measurement }\end{array}$} & \multicolumn{2}{|c|}{ Boys } \\
\hline & & $\begin{array}{c}\text { Before rehabilitation } \\
\text { n-18 }\end{array}$ & $\begin{array}{c}\text { After rehabilitation } \\
n-18\end{array}$ \\
\hline Total number of errors & un. & $4.28 \pm 0.19$ & $3.08 \pm 0.14$ \\
\hline Mental performance & un & $4.33 \pm 0.19$ & $5.50 \pm 0.25$ \\
\hline The average time of reaction & $\mathrm{ms}$ & $427.39 \pm 11.07$ & $316.27 \pm 8.19$ \\
\hline $\begin{array}{l}\text { Stability of attention and RAM } \\
\text { intelligent attention) }\end{array}$ & un & $4.33 \pm 0.19$ & $5.55 \pm 0.25$ \\
\hline Number of false reactions & un. & $2.67 \pm 0.26$ & $1.95 \pm 0.19$ \\
\hline Number of passes & un & $1.61 \pm 0.13$ & $1.18 \pm 0.09$ \\
\hline \multirow[b]{2}{*}{ Indicators } & \multirow{2}{*}{$\begin{array}{c}\text { Unites of } \\
\text { measurement }\end{array}$} & \multicolumn{2}{|c|}{ Girls } \\
\hline & & $\begin{array}{c}\text { Before rehabilitation } \\
\mathrm{n}-22\end{array}$ & $\begin{array}{c}\text { After rehabilitation } \\
\mathbf{n - 2 2}\end{array}$ \\
\hline Total number of errors & un & $4.18 \pm 0.22$ & $3.14 \pm 0.17$ \\
\hline Mental performance & un & $4.23 \pm 0.22$ & $5.24 \pm 0.28$ \\
\hline The average time of reaction & $\mathrm{ms}$ & $425.68 \pm 11.89$ & $323.52 \pm 9.03$ \\
\hline $\begin{array}{l}\text { Stability of attention and RAM } \\
\text { intelligent attention) }\end{array}$ & un & $4.23 \pm 0.22$ & $5.28 \pm 0.28$ \\
\hline Number of false reactions & un & $2.91 \pm 0.17$ & $2.24 \pm 0.13$ \\
\hline Number of passes & un & $1.32 \pm 0.11$ & $0.99 \pm 0.08$ \\
\hline
\end{tabular}

The results of the study of the influence of the developed complex technological process of physical exercises on the indicators characterizing the sound version of the correction test for children with visual pathology at the age of 15-16 years are given in table 4 .

Table 4. The influence of rehabilitation physical exercises on the indicators of the sound version of the correction test in children with visual impairments at the age of 15-16.

\begin{tabular}{|c|c|c|c|}
\hline \multirow[t]{2}{*}{ Indicators } & \multirow{2}{*}{$\begin{array}{c}\text { Unites of } \\
\text { measurement }\end{array}$} & \multicolumn{2}{|c|}{ Boys } \\
\hline & & $\begin{array}{l}\text { Before rehabilitation } \\
n-12\end{array}$ & $\begin{array}{c}\text { After rehabilitation } \\
n-12\end{array}$ \\
\hline Total number of errors & un. & $2.08 \pm 0.18$ & $1.42 \pm 0.12$ \\
\hline Mental performance & un & $2.17 \pm 0.18$ & $2.86 \pm 0.23$ \\
\hline The average time of reaction & $\mathrm{ms}$ & $429.33 \pm 5.58$ & $296.24 \pm 3.85$ \\
\hline $\begin{array}{l}\text { Stability of attention and RAM } \\
\text { intelligent attention) }\end{array}$ & un & $2.17 \pm 0.18$ & $2.80 \pm 0.23$ \\
\hline Number of false reactions & un & $1.83 \pm 0.18$ & $1.25 \pm 0.12$ \\
\hline Number of passes & un & $0.33 \pm 0.09$ & $0.23 \pm 0.06$ \\
\hline \multirow[b]{2}{*}{ Indicators } & \multirow{2}{*}{$\begin{array}{c}\text { Unites of } \\
\text { measurement }\end{array}$} & \multicolumn{2}{|c|}{ Girls } \\
\hline & & $\begin{array}{c}\text { Before rehabilitation } \\
n-18\end{array}$ & $\begin{array}{c}\text { After rehabilitation } \\
n-18\end{array}$ \\
\hline Total number of errors & un & $0.83 \pm 0.13$ & $0.58 \pm 0.09$ \\
\hline Mental performance & un & $0.78 \pm 0.13$ & $1.00 \pm 0.17$ \\
\hline The average time of reaction & $\mathrm{ms}$ & $447.44 \pm 9.07$ & $322.16 \pm 6.53$ \\
\hline $\begin{array}{l}\text { Stability of attention and RAM } \\
\text { intelligent attention) }\end{array}$ & un & $0.83 \pm 0.19$ & $1.08 \pm 0.25$ \\
\hline Number of false reactions & un. & $0.78 \pm 0.19$ & $0.56 \pm 0.14$ \\
\hline Number of passes & un & $0.39 \pm 0.06$ & $0.28 \pm 0.05$ \\
\hline
\end{tabular}

In children at the age of 15-16 years with visual impairments, a set of phased physical exercises was performed, which also showed a positive result in the control performance of the indicators characterizing the sound version of the correction test. In boys at the age of 15 16 years with visual impairments, the total number of errors after a set of rehabilitation 
measures is reduced by $16.48 \%$, and in girls - by $43.10 \%$; the average reaction time - in boys by $44.93 \%$, in girls - by $38.89 \%$; the number of false reactions - in boys by $46.46 \%$, in girls - by $39.20 \%$; the number of passes - for boys by $43.48 \%$, for girls - by $39.29 \%$. After a set of phased physical exercises in children at the age of 15-16 years with visual impairments increases mental performance in boys by $31.80 \%$, in girls - by $28.21 \%$; intellectual attention - by $29.03 \%$ in boys and $30.12 \%$ in girls.

The results of the study of the effectiveness of step-by-step rehabilitation technology of physical exercises in children 10-14 years with visual impairment on the indicators characterizing contact coordination are shown in table 5.

Table 5. The influence of the rehabilitation program of physical exercises on indicators of contact coordinationometry in children of 10-14 years with visual impairments.

\begin{tabular}{|l|c|c|c|}
\hline \multirow{2}{*}{ Indicators } & Unites of & \multicolumn{2}{|c|}{ Boys } \\
\cline { 3 - 4 } & measurement & $\begin{array}{c}\text { Before rehabilitation } \\
\mathbf{n - 1 8}\end{array}$ & $\begin{array}{c}\text { After rehabilitation } \\
\text { n-18 }\end{array}$ \\
\hline Total touch time & $\mathrm{s}$ & $11.50 \pm 0.72$ & $10.35 \pm 0.64$ \\
\hline Amount of touch & un & $60.89 \pm 2.72$ & $55.41 \pm 2.47$ \\
\hline Touch time & $\mathrm{s}$ & $0.37 \pm 0.04$ & $0.33 \pm 0.04$ \\
\hline \multirow{2}{*}{ Indicators } & Unites of \\
& measurement & Before rehabilitation & After rehabilitation \\
\cline { 3 - 4 } & & $\mathrm{n}-22$ & $\mathbf{n}-22$ \\
\hline Total touch time & $\mathrm{s}$ & $12.01 \pm 0.76$ & $10.21 \pm 0.64$ \\
\hline Amount of touch & $\mathrm{s}$ & $63.82 \pm 3.80$ & $54.88 \pm 3.26$ \\
\hline Touch time & & $0.60 \pm 0.07$ & $0.52 \pm 0.06$ \\
\hline
\end{tabular}

The complex phased technological rehabilitation of children at the age of 10-14 with visual impairment, which had been developed by us, showed the expediency of its use in the rehabilitation of children according to the indicators of contact coordination. Both boys with visual impairment and girls with visual impairment have a tendency to normalize the indicators that characterize contact coordination. The total contact time for boys decreases by $11.11 \%$, for girls - by $17.63 \%$; the number of touches by $9.89 \%$ in boys and $16.29 \%$ in girls; touch time for boys by $12.12 \%$, for girls - by $15.38 \%$.

As can be seen from the data in the table. 5 the proposed step-by-step comprehensive rehabilitation technology is effective for girls - by $58.69 \%, 64.71 \%$ and $26.90 \%$, respectively, in terms of the total number of touches, the number of touches and the time of touches. Therefore, this complex must be used primarily among girls, as such, which is more effective than for boys.

The results of studies to determine the effectiveness of rehabilitation measures to perform indicators of contact coordination at the age of 15-16 years with visual impairment are shown in table 6.

Table 6. The influence of the rehabilitation program of physical exercises on indicators of contact coordinationometry in children of 15-16 years with visual impairments.

\begin{tabular}{|l|c|c|c|}
\hline \multirow{2}{*}{ Indicators } & Unites of & \multicolumn{2}{|c|}{ Boys } \\
\cline { 3 - 4 } & measurement & $\begin{array}{c}\text { Before rehabilitation } \\
\mathbf{n - 1 2}\end{array}$ & $\begin{array}{c}\text { After rehabilitation } \\
\text { n-12 }\end{array}$ \\
\hline Total touch time & $\mathrm{s}$ & $15.42 \pm 0.59$ & $12.34 \pm 0.47$ \\
\hline Amount of touch & un & $75.00 \pm 2.30$ & $60.75 \pm 1.86$ \\
\hline Touch time & $\mathrm{s}$ & \multicolumn{2}{|c|}{ Девочки } \\
\hline \multirow{2}{*}{ Indicators } & $\begin{array}{c}\text { Unites of } \\
\text { measurement }\end{array}$ & $\begin{array}{c}\text { Before rehabilitation } \\
\mathbf{n}-\mathbf{1 8}\end{array}$ & $\begin{array}{c}\text { After rehabilitation } \\
\mathbf{n}-18\end{array}$ \\
\cline { 3 - 4 } & & $15.93 \pm 0.39$ & $13.70 \pm 0.33$ \\
\hline Total touch time & $\mathrm{s}$ & $65.67 \pm 2.65$ & $56.47 \pm 2.28$ \\
\hline Amount of touch & $\mathrm{un}$ & $1.10 \pm 0.09$ & $0.96 \pm 0.07$ \\
\hline Touch time & $\mathrm{s}$ & &
\end{tabular}


The comprehensive phased rehabilitation measures carried out for children at the age of 15-16 years with visual impairment also proved to be effective in performing indicators of contact coordination, in the process of rehabilitation there was a tendency to normalize the indicators by reducing the total contact time for boys $16.29 \%$; the number of touches decreased for boys by $23.46 \%$, for girls - by $16.29 \%$; the time of touches also decreased by $25.00 \%$ in boys and by $14.58 \%$ in girls.

As can be seen from the obtained and given data in table 6 . There are more significant improvements obtained in boys at the age of 15-16 years with visual impairment than in girls. Girls lag behind boys from the total time of touches by $53.32 \%$, in terms of the number of touches boys are ahead of girls by $44.01 \%$, in terms of time of touches - by $71.47 \%$.

The results of the study of the strength and endurance of the hands in children at the age of 10-14 years with visual impairment are shown in table 7.

Table 7. The influence of the exercise program on indicators of research of force and endurance of hands in children with visual impairment at the age of 10-14 years.

\begin{tabular}{|c|c|c|c|}
\hline \multirow[t]{2}{*}{ Indicators } & \multirow{2}{*}{$\begin{array}{r}\text { Unites of } \\
\text { measureme } \\
\text { nt }\end{array}$} & \multicolumn{2}{|c|}{ Boys } \\
\hline & & $\begin{array}{c}\text { Before rehabilitation } \\
n-18\end{array}$ & $\begin{array}{c}\text { After rehabilitation } \\
n-18\end{array}$ \\
\hline Maximum muscle strength & $\mathrm{H}$ & $17.83 \pm 0.52$ & $23.18 \pm 0.67$ \\
\hline The indicators of endurance & $\%$ & $85.63 \pm 3.30$ & $88.20 \pm 3.40$ \\
\hline Retention threshold & $\mathrm{H}$ & $8.94 \pm 0.42$ & $11.63 \pm 0.55$ \\
\hline Retention duration & $\mathrm{S}$ & $10.21 \pm 0.63$ & $13.06 \pm 0.80$ \\
\hline Retention duration within & $\mathrm{S}$ & $9.11 \pm 0.90$ & $11.75 \pm 1.16$ \\
\hline \multirow[b]{2}{*}{ Indicators } & \multirow{2}{*}{$\begin{array}{c}\text { Unites of } \\
\text { measureme } \\
\text { nt }\end{array}$} & \multicolumn{2}{|c|}{ Girls } \\
\hline & & $\begin{array}{c}\text { Before rehabilitation } \\
n-22\end{array}$ & $\begin{array}{c}\text { After rehabilitation } \\
n-22\end{array}$ \\
\hline Maximum muscle strength & $\mathrm{H}$ & $18.00 \pm 1.79$ & $23.04 \pm 2.29$ \\
\hline The indicators of endurance & $\%$ & $91.80 \pm 1.67$ & $93.64 \pm 1.71$ \\
\hline Retention threshold & $\mathrm{H}$ & $9.06 \pm 0.90$ & $11.60 \pm 1.15$ \\
\hline Retention duration & $\mathrm{S}$ & $12.30 \pm 0.44$ & $15.63 \pm 0.55$ \\
\hline Retention duration within & $\mathrm{S}$ & $11.60 \pm 0.35$ & $14.62 \pm 0.44$ \\
\hline
\end{tabular}

The methods of gradual correction of indicators of force and endurance of hands in children of 10-14 years with visual impairment which were carried out by us, showed the efficiency both in boys, and in girls at the age of 10-14 years, at the same time the maximum muscular force increases by $30 \%$ and $28,0 \%$, respectively; endurance in boys increases by $3.0 \%$ and in girls by $2.0 \%$; the lower retention threshold increases in boys by $30.09 \%$, in girls by $28.04 \%$; the duration of retention and the duration of retention within boys increases by $27.91 \%$ and $28.98 \%$, respectively, in girls - by $27.07 \%$ and $26.03 \%$, respectively.

The results of the study of the strength and endurance of the hands in children at the age of 15-16 years with visual impairment, among whom a comprehensive phased exercise program was conducted, are shown in table 8 .

The strength and endurance of the hands in children at the age of 15-16 years with visual impairment also increase after the rehabilitation activities carried out with the developed technology. The maximum muscular strength in boys with visual impairment increases after the phased contact technology of physical exercises by $34.98 \%$, in girls with visual impairment - by $27.99 \%$; endurance index - in boys by $3.0 \%$, in girls - by $2.0 \%$; compliance with the lower threshold, retention increases by $35.32 \%$ for boys and $28.04 \%$ for girls; the duration of retention increases in boys by $35.0 \%$, in girls - by $28.02 \%$ and the duration of retention within increases in boys by $34.0 \%$, in girls - by $26.96 \%$. 
Table 8. The influence of the exercise program on indicators of research of force and endurance of hands in children with visual impairment at the age of 10-14 years.

\begin{tabular}{|c|c|c|c|}
\hline \multirow[t]{2}{*}{ Indicators } & \multirow{2}{*}{$\begin{array}{c}\text { Unites of } \\
\text { measurem } \\
\text { ent }\end{array}$} & \multicolumn{2}{|c|}{ Boys } \\
\hline & & $\begin{array}{c}\text { Before } \\
\text { rehabilitation } \\
\text { n-12 }\end{array}$ & $\begin{array}{l}\text { After rehabilitation } \\
\text { n-12 }\end{array}$ \\
\hline Maximum muscle strength & $\mathrm{H}$ & $32,42 \pm 1,33$ & $43,76 \pm 1,79$ \\
\hline The indicators of endurance & $\%$ & $97,42 \pm 0,89$ & $100,34 \pm 0,91$ \\
\hline Retention threshold & $\mathrm{H}$ & $16,25 \pm 1,77$ & $21,94 \pm 2,39$ \\
\hline Retention duration & $\mathrm{S}$ & $21,34 \pm 1,14$ & $28,81 \pm 1,54$ \\
\hline Retention duration within & $\mathrm{S}$ & $20,91 \pm 1,20$ & $28,02 \pm 1,60$ \\
\hline \multirow{2}{*}{ Indicators } & \multirow{2}{*}{$\begin{array}{c}\text { Unites of } \\
\text { measurem } \\
\text { ent }\end{array}$} & \multicolumn{2}{|c|}{ Girls } \\
\hline & & $\begin{array}{c}\text { Before } \\
\text { rehabilitation } \\
\text { n-18 }\end{array}$ & $\begin{array}{l}\text { After rehabilitation } \\
\mathbf{n}-18\end{array}$ \\
\hline Maximum muscle strength & $\mathrm{H}$ & $16,22 \pm 0,97$ & $20,76 \pm 1,24$ \\
\hline The indicators of endurance & $\%$ & $78,39 \pm 2,59$ & $79,96 \pm 2,64$ \\
\hline Retention threshold & $\mathrm{H}$ & $8,13 \pm 0,69$ & $10,41 \pm 0,88$ \\
\hline Retention duration & $\mathrm{S}$ & $10,03 \pm 0,63$ & $12,84 \pm 0,81$ \\
\hline Retention duration within & $\mathrm{S}$ & $7,38 \pm 0,65$ & $9,37 \pm 0,82$ \\
\hline
\end{tabular}

The results of the studied indicators characterizing the tapping test in children at the age of 10-14 years with visual impairment after the rehabilitation activities provided by the rehabilitation method of physical exercises are shown in table 9.

Table 9. The influence of complex rehabilitation physical exercises on indicators of the tapping test at children with visual impairment at the age of 10-14 years.

\begin{tabular}{|c|c|c|c|}
\hline \multirow[t]{2}{*}{ Indicators } & \multirow{2}{*}{$\begin{array}{c}\text { Unites of } \\
\text { measurement }\end{array}$} & \multicolumn{2}{|c|}{ Boys } \\
\hline & & $\begin{array}{c}\text { Before } \\
\text { rehabilitation } \\
\text { n-18 }\end{array}$ & $\begin{array}{c}\text { After rehabilitation } \\
n-18\end{array}$ \\
\hline Meduim frequency & $\mathrm{Hz}$ & $4.70 \pm 0.13$ & $5.41 \pm 0.15$ \\
\hline The level of the initial pace of work & $\mathrm{Hz}$ & $5.10 \pm 0.10$ & $5.81 \pm 0.11$ \\
\hline Average inter-stroke interval & $\mathrm{Hz}$ & $212.37 \pm 7.60$ & $180.51 \pm 6.46$ \\
\hline Number of strokes & un. & $140.94 \pm 4.01$ & $159.27 \pm 4.54$ \\
\hline \multirow[b]{2}{*}{ Indicators } & \multirow{2}{*}{$\begin{array}{c}\text { Unites of } \\
\text { measurement }\end{array}$} & \multicolumn{2}{|c|}{ Girls } \\
\hline & & $\begin{array}{c}\text { Before } \\
\text { rehabilitation } \\
\text { n-22 } \\
\end{array}$ & $\begin{array}{c}\text { After rehabilitation } \\
n-22\end{array}$ \\
\hline Meduim frequency & $\mathrm{Hz}$ & $4.50 \pm 0.09$ & $5.04 \pm 0.10$ \\
\hline The level of the initial pace of work & $\mathrm{Hz}$ & $5.20 \pm 0.13$ & $5.78 \pm 0.14$ \\
\hline Average inter-stroke interval & $\mathrm{Hz}$ & $232.63 \pm 5.00$ & $204.72 \pm 4.40$ \\
\hline Number of strokes & un. & $134.59 \pm 3.07$ & $150.74 \pm 3.44$ \\
\hline
\end{tabular}

Carrying out of a complex of rehabilitation actions in children of 10-14 years with visual impairment positively influences the indicators characterizing force of a nervous system in these children. In children at the age of 10-14 years with a pathology of sight the level of average frequency increases by $15,11 \%$ in boys and by $12,0 \%$ - in girls; the level of the initial 
rate of work in boys increases by $13.92 \%$, in girls - by $11.15 \%$; the number of strokes increases in boys by $13.0 \%$, in girls - by $12.0 \%$; the average interstitial interval decreases by $17.65 \%$ in boys and by $13.63 \%$ in girls. The level of positive changes in the indicators characterizing the quality of the tapping test are the results in table. 9. All this indicates the positive impact of the developed technology of rehabilitation measures.

The results of the study of the impact of the developed phased complex of technology for the rehabilitation of children aged 15-16 with visual impairment on the indicators of the tapping test are shown in table 10.

Table 10. The influence of complex rehabilitation physical exercises on indicators of the tapping test at children with visual impairment at the age of 10-14 years.

\begin{tabular}{|c|c|c|c|}
\hline \multirow[t]{2}{*}{ Indicators } & \multirow{2}{*}{$\begin{array}{c}\text { Unites of } \\
\text { measurement }\end{array}$} & \multicolumn{2}{|c|}{ Boys } \\
\hline & & $\begin{array}{c}\text { Before } \\
\text { rehabilitation } \\
\text { n-12 } \\
\end{array}$ & $\begin{array}{c}\text { After rehabilitation } \\
n-12\end{array}$ \\
\hline Meduim frequency & $\mathrm{Hz}$ & $5.10 \pm 0.19$ & $6.53 \pm 0.24$ \\
\hline The level of the initial pace of work & $\mathrm{Hz}$ & $5.30 \pm 0.13$ & $6.78 \pm 0.17$ \\
\hline Average inter-stroke interval & $\mathrm{Hz}$ & $200.75 \pm 6.73$ & $146.55 \pm 4.91$ \\
\hline Number of strokes & un. & $150.17 \pm 3.90$ & $189.21 \pm 4.91$ \\
\hline \multirow[t]{2}{*}{ Indicators } & \multirow{2}{*}{$\begin{array}{c}\text { Unites of } \\
\text { measurement }\end{array}$} & \multicolumn{2}{|c|}{ Girls } \\
\hline & & $\begin{array}{c}\text { Before } \\
\text { rehabilitation } \\
\text { n-12 }\end{array}$ & $\begin{array}{c}\text { After rehabilitation } \\
n-12\end{array}$ \\
\hline Meduim frequency & $\mathrm{Hz}$ & $5.10 \pm 0.19$ & $6.53 \pm 0.24$ \\
\hline The level of the initial pace of work & $\mathrm{Hz}$ & $5.30 \pm 0.13$ & $6.78 \pm 0.17$ \\
\hline Average inter-stroke interval & $\mathrm{Hz}$ & $200.75 \pm 6.73$ & $146.55 \pm 4.91$ \\
\hline Number of strokes & un. & $150.17 \pm 3.90$ & $189.21 \pm 4.91$ \\
\hline
\end{tabular}

As in the previous group of children, in the next (children at the age of 15-16 years) group of children, the similar indicators were received after the activities. Thus, in boys at the age of 15-16 years with pathology of vision after rehabilitation, the average frequency increases by $28.04 \%$, in girls - by $22.08 \%$; the level of the initial rate of work increases by $27.92 \%$ for boys and $21.0 \%$ for girls; the number of strokes increases by $26.0 \%$ in boys and girls - by $22.0 \%$, for the reduction of the average inter-stroke interval by $36.98 \%$ in boys and by $32.86 \%$ in girls.

\section{Conclusions}

Thus, we developed and implemented a phased set of rehabilitation exercises for children 1016 years with visual impairment proved to be effective, which makes it possible to recommend its use to influence the psychophysical status of children in specialized boarding schools among children 10-16 years with visual impairments. The effectiveness of the use of this complex in the process of rehabilitation physical education on the psychophysical status of children with visual impairment is confirmed by the positive results of our study. We believe that further study and mastery of this technique will be a necessary condition for the active development of psychomotor skills in children with visual impairments.

\section{References}

1. D.V. Dychko, V.E. Bobyrev, V.S.Vasilevsky, V.V.Burov,. Bulletin of problems of biology and medicine: Ukrainian scientific-practical journal, 4 (158), 385-388 (2020) DOI 1029254 
2. V.V. Dychko, V.E. Bobyrev, Yu.S. Klimenko, Ukrainian Journal of Medicine, Biology and Sports, 4, 4 (20), 301 - 306 (2019) DOI: 10.26693 / mbs04.04.301

3. N.D.Pilkevich, V.A. Markovskaya, O.V. Yavorskaya, E.A. Pilkevich, R.R. Khabibullin, International research journal, 4 (106), 180-184 (2021) DOI: 10.23670/IRJ.2021.106.4.059

4. N.V. Shutova, O.V. Suvorova, M.V. Arkhipova, Perspectives of Science and Education, 39 (3), 300-314 (2019) DOI: 10.32744/pse.2019.3.23

5. E.A. Dychko, I.V. Kushakova, European science. Scientific journal, 4, 20 - 27 (2019)

6. S. Cueto, J. Prieto Saborit, P. Nistal, C. Abelairas-Gómez, R. Barcala Furelos, S. García, Perceptual and Motor Skills, 124 (2017) DOI:10.1177/0031512517705534

7. M.V. Arkhipova, E.E. Belova, N.V. Shutova, Advances in intelligent Systems and Computing, 677, 113-121 (2018) DOI: 10.1007/978-3-319-67843-6_14

8. L.S. Namazova- Baranova, K.A. Yeletskaya, Ye.V. Kaitukova, S.G. Makarova, Pedagogical pharmacy, 15(4), 333-342 (2018)

9. N.V. Babkina, Clinical Psychology and Special Education, 7 (4), 1-18 (2018) DOI: 10.17759/psycljn.2018070401

10. L.I. Alifanova, O.V. Koranleva, Modern Research of Social Problems, 3-2(59), 328338 (2016)

11. I.A. Korobeinikov, N.V. Babkina, Consulting psychology and psychotherapy, 25 (4), 11-22 (2017)

12. V.I. Lubovskyi, I.A. Korobeinikov, S.M. Valiavko, Psychological science and education, 21(4), 50-60 (2016)

13. G. Cappagli, S. Finocchiett, E. Cocchi, G. Giammari, R. Zumiani, A.V. Cuppone, G. Baud-Bovy, M. Gori, Scientific Reports, 9, 3303 (2019) DOI:10.1038/s41598-01939981-X 